\title{
The Germplasm as a Stereochemic System-II*
}

\author{
Every Individual is a Chemical Entity That Differs in Characteristic Particulars from Every Other
}

By Edward Tyson Reichert, University of Pennsylvania

Concluded from Scientific American Supplement No. 2023, Page 227, October 10, 1914

\begin{abstract}
C. THE GERMPIASM A STELEOCHEMIC SYS'TEM, THAT IS, PHYSICO-CHEMICAL SYSTEM THAT IS PAR'TICULARI2E JiY THE CHAHACTERS OF ITS STEREOISOMERS AN THE ARRANGHMENTS OF I'S COMPONENTS IN THE THRE DIMENSIONS OF SPACE.
\end{abstract}

If, during the progress of development, there arise the multiple forms of differentiated protoplasm that ar represented in the nerve cells, muscles, glands, etc. which exhibit such diversity of form, functions, composition and products, each part being correlated to other parts by the agency of tissue products, it is logical to assume that in the development of the ovaries and assume that in the development of the ovaries and dow them with the attribute of producing a form of protoplasin that embodies in a germinal state the fundamental peculiar stereoisomerides and the peculiar arrangement or phases of the associated proteins, fats, carbohydrates and other substances which inherently characterize the organism; and, moreover, that owing to the influences of the products of activity of the various tissues upon these organs, such changes in the organism as give rise to acquired characters may, through the actions of modified or new tissue products or foreign substances, affect the operations of these organs and thus alter the gern plassm and consequently become manifested in some form in the off spring. The ovule in its incipiency is cunceived to be comparable to a complex unequilibrated solution in which changes go on until the attaimment of ful development, at which time it is equilibrated and remain inactive because of the absence of some disturbing influence, but in which energy-reactions may be initiated physically, mechanieally or chemically, and proceed according to definite physico-chemical laws in definite directions to a definite end. As for instance, when solution of boiled starch and diastase is at a temperature below the minimal of activity and the temperature is raised, causing immediate developmental activation; or when the equilibrated molecules of nitroglycerine are exploded by percussion; or when an equilıbrated maltosedextrose-maltase solution is rendered active by dilution with water.

The nature of the yermplasm or transmissive material that serves as the bridge of continuity between parents and offspring has been the subject of speculation from time immemorial. Such hypotheses and theories as hav been advanced have had reference almost wholly to its physical constitution or ultimate morphological structure. Most of them are micromeric, that is, they hold that the germplasm as made up of infinite number of discrete ultramicroscopic particles which are endowed discrete ultramicroscopic particles which are endowed A considerable degree of ingenuity has been displayed in their formulation. 'Thus, we have the "organic mole cules" of Buffon, the "nicrozymes" of Bèchamp, the "life units" of Spencer, the "plastidules" of Maggi, the "bioplasts" of Altmann, the "stirps" of Galton, the "gemmules" of Darwin, the "biophors" of Weismann, the "pangens" of DeVries, etc., each author attributing to the units certain inherent peculiarities. To the foregoing might be added particularly the conceptions that belong to the chemical category, such as the "chemism" of LeDantec and the "physico-chemical" theory of Delage. Some of these conceptions are so fanciful in the light of modern science as to be unworthy of more than passing consideration, while none of them has led anywhere beyond the field of speculation and reasoning. Even the very recent and extremely interesting and important additions to our knowledge of the histological phenomena of the developing ovum, especially of the chromosomes, have not taken us appreciably nearer the ultimate constitution or mechanism of the germplasm, or even to the nature of the reactions which occur immediately antecedent to and cause the formation of the chromosomes.

A theory to be ideal must not only have as its basis also be capable of substantiation by laboratory investigation. Given as the basis of scientific study a germplasn that has inherently the power of development; that is in that has inherently the power of development; that is in
the form of a stereochemic system that is peculiar to the the form of a stereochemic systern that is peculiar to the
organism; that is highly impressionable to stimuli; and that has the marked plasticity that is inherent to organic colloidal matter, we have all the postulates that are
needed as a foundation upon which according to the laws

Read by title at the meeting of the American Philosophical Society, April 25th, 1914, and in full before the Society of Normal
and $\mathrm{Pa}$ hological Physiology of the University of Pennsylvania, and Pa hological of physical chemistry can be built a logical explanation of the essential fundamental elements of the mechanism of heredity.

The inherert potentiality that determines the development of the egg along a line of definite sequential processes must be recognized as being common to both animate and inanimate matter and subject to the same laws, so that the phenomena of living and dead matter are inseparably linked and reciprocally explanatory. The typical condition of matter of definite composition is crystalline, and the crystalline form is the result of decrystalline, and the crystalline form is the result of de-
velopment that becomes manifested in a separation and velopment that becomes manifested in a separation and
orderly and progressive arrangements of components in the three dimensions of space. Having a homogeneous solution of various selected crystalline substances of appropriate chemical composition and constitution, and given conditions attendant to crystallization, the successive stages of crystalline development will proceed along fixed and definitely recognized lines, and the interactions and interaction-relationships between the various substances constituting the physico-chemical mechanism become obvious to a greater or less extent in the peculiarities of form, composition and other properties of the crystals. Having in the germplasm an analogous physicochemical system, but one which is markedly different especially because of its organic and colloidal character tivity, infitely greater molecular complexity and sensiin conformity with the same laws along definite lines, but they are for perfectly nanifest reasons more complex and varied, more difficult of analysis, and necessarily in many varied, more difficult of analysis, and necessarily in many
very important respects ruite different. Each step in very important respects quite different. Each step in
this orderly development leads not merely to changes of the physico-chemical mechanism by the modification, rearrangement, or splitting off of component parts, but also to alterations which automatically determine the characters of the next succeeding step, and so on to the establishment of physico-chemical equilibrium and the consequent termination of the reactions.

In living matter the chemical processes are dependent to a pre-eminent degree upon enzynies that are formed by the different kinds of protoplasm to serve as implements to carry out operations that are essential to their existence, and such enzymes are modifiable in quantity and quality in accordance with changes in internal and external conditions. The nature of both reactions and products of enzymic action depends upon the constitution and composition of the physico-chemical mechanism of which the enzyme is an integral part. Whether or not at each step of serial reactions a portion of pre-existing enzyme is merely modified or a new enzyme is formed which constitutes an essential part of the particular phase of the reactions is not known, but that one or the other occurs is apparently without question. It has long been established that some of the lower organisms, such as the yeast plant, have the property of modifying the characters of the enzymes produced in relation to varying conditions; recent studies of the animal organism show that the same phenomenon occurs in both tissues and blood; and our knowledge of the processes concerned in the cutabolism and anabolism of complex substances, such as starch, is fully in support of such a conception. In other words, as each step of development is reached the alterations which occur in the physico-chenical mechanism absolutely automatically predetermine the characters of the changes of the next succeeding step, and so on to the end. Hence it follows that the peculiarities of any given physico-iehemical mechanism predetermine the characters of the phenomena which ensue under given conditions.

An illustration of the probable modus operandi of such a mechanism is found in the phenomena of the synthesis and analysis of starch: During the production of starch through the agency of the chloroplast or leucoplast we conceive that there are instituted a predetermined orderly, independent and interdependent series of reactions, the first of which is manifested in an interaction between water and carbon dioxide through the agency of an enzyme in the form of an oxidase to form formaldehyde. During this process there is formed another enzyme, which tentatively may be designated an aldehydase, that reacts with formaldehyde and by polymerization and condensation of six molecules gives rise to a simple sugar, such as dextrose. At the same time, another enzym appears in the form of maltase, which reacting with the dextrose causes the formation of maltose, during which reaction another enzyme, a dextrinase, is produced which reacts with the maltose to yield dextrin. Going on with this reaction another enzyme which may be designated an amylase appears, which reacting with the dextrin forms soluble starch. During this stage there arises another enzyme, a coagulase, which converts the starch from the soluble to the insoluble form or ordinary starch. At this stage the series of reactions have reached their end because a state of physico-chemical equilibrium has become established, the ultimate purpose of the processes being attained, that is a form of pabulum of extremely high nutritive value and of extremely low molecular pressure, even in soluble form, so that it may entirely and rapidly disappear without disturbance of physico-chemical equilibrium in the starch-bearing cells. The mechanism concerned in starch-formation is, without doubt, paralleled in the synthesis of proteins, fats and other complex organic substances, and it is but a step from the individual serial processes concerned in the formation of each of these substances to associated processes whereby there are formed and combined the various substances that constitute the organic structural components of protoplasm. Moreover, such serial processes are reversible at any stage, and so simple a modification as a change in the per cent of water may, as in the maltose-dextroseglucase reaction, cause a synthetic change.

In vitro in both synthetic and analytic processes like those which constitute serial steps in the building up and breaking down of starch, protein, fat and other complex organic substances there does not occur in any reaction, as far as known, either a transformation or a production of enzyme such as occurs in vino, hence, when a single enzyme is present it carries out but one step of the reactions, but when, as in the case of diastases as ordinarily prepared, the enzyme is not a single substance or unit budy but a composite of a number of enzymes or modifications of a given basic enzyme, serial steps may occur as in vivo. 'Thus, if only a single enzyme be present, formaldehyde may be converted into a monosaccharose, or a monosaccharose into a disaccharose, or a disaccharose into a polysaccharose such as dextrin, or dextrin into a higher form of polysaccharose such as soluble starch, according to the enzyme or modified enzyme and initial substance present; or the reverse of any one of these processes may occur if proper conditions are present, but never do any two successive progressive or regressive steps occur unless through the agency of two different or modified forms of enzymes present.

It will thus be apparent that the first step of synthesis is determined by the character of the initial physicochemical mechanism and that all subsequent reactions under given conditions are definitely predetermined; in other words, the entire train of reactions depends inherently upon the nature of the initial physico-chemical mechanism of which the enzyme that starts the serial changes is an integral part.

Having a specific stereochemic system, such a system in accordance with the laws of physical-chemistry can exist in either a latent or active state, and that when in an active state the reaction or reactions are always in the direction of the establishment of enuilibrium of solution, every reaction or series of reactions being as definitely predetermined as is every reaction familiar to the inorganic chemist. The germplasm in the form in which it is secreted may be regarded as being in the nature of an exceedingly complex stereochemic system which is from its incipiency, or very soon, in a state of physicochemical unequilibrium, and in which, as a consequence, reactions are set up which are manifested especially in histological developments that ultimately characterize the fully developed ovule, at which time a state of physicochemical equilibrium is established, as is evident by the arrested developmental activities. This state of physicochemical equilibrium of the matured ovule may be instantly changed to one leading to serial definitely predetermined reactions by means of an activating substance or condition, such as certain ions or inorganic salts, a permatozoon, or a needle prick, by initiating the first tep of the reactions, the nature of the succeeding reactions being predetermined primarily by the inherent nature of the physico-chemical system and secondarily by the factor that activates it. In other words, from this initial stereochemic system there arises a complex heterogeneous system that ultimately is morphologically expressed in the histology of the matured ovule and from which are formed a composite of correlated, independent, interdependentand differentiated masses which represent different phases of the components of the initial system 
which have been modified not only physico-chemically as expressed by changes in physical, mechanical and chemical properties, but also in developmental energies; and from this composite are developed successively other systems.

Owing to the great impressionability and plasticity of such an exceedingly complex stereochemic system as the germplasm it follows that the germplasm must be extremely sensitive to changes in internal and external contremely sensitive to changes in internal and external con-
ditions, and that its operations and products may be so ditions, and that its operations and products may be so
materially modified by changes in its molecular arrangements or components as to give rise to variables that are manifested in the transmutability of sex, variations, fluctuations, mutations, deformities, retrogressions, tumor formation, immunities, ete.

Assuming in accordance with our conception that the germplasm is in its incipiency an unequilibrated stereochemic system that is characteristic of the inherent, fundamental stereochemic system of the parent, it folfows, as a corollary, that having a highly specialized form lows, as a corollary, that having a highly specialized form
of parental structural material with peculiar energyproperties the offspring must of necessity possess essentially the same fundamental characteristics as the parents when normal fecundation has occurred, and that it would be quite as impossible to have any other result than in ordinary chemical reactions under given conditions of experiment. The essential characters of the building material as regards substances, arrangements and energy-
properties are definitely fixed within narrow limits of properties
variation.

That the peculiar forms of stereoisomerides or intimately related bodies that are inherent in the parent are conveyed in the germplasm to the offspring, and
hence of necessity serve to distinguish a given form of germplasm from that of any other species or genus, and that the stereochemic conception of the nature of the germplasm is capable of laboratory demonstration, are instanced in the results of the investigations of Kossell instanced in the results of the investigations of Kossel
and his students who found that simple forms of protein known as protamins, obtained from the spermatozoa of different species of fish are different, each being apparently of a form peculiar to the source. Here is on substance at least that seems to be in specific stereoisomeric forms in the sperm of different species, which obviously must affect the properties of the germplasm, an which when brought in contact with the germplasm of the egg plays its part in determining the phenomena of development. Moreover, by the "precipitin reaction" mothod Blakeslee and Gortner have found evidence that is consistent with the conclusion that there are not only "species proteins" but also "sex proteins," and this re ceives support in a number of very recent investigations, especially those of Steinach who found that the corresponding hormones secreted by the ovaries and testicle are different, and that by virtue of these differences the secondary sexual characters, female and male, are deter

\section{A French Experiment for Preventing Fogs}

The municipality of Lyons has set aside a certai sum to carry on experiments for preventing local fogs proposed by M. Georges Onofrio, director of the Fourvière Observatory of that city. This well-known me teorologist has devoted much study to the fogs that cover Lyons for many days during the cold season, and has beeome convinced that these fogs may be lessened, if not entirely obviated. It may be noted, in contradistinction to general fogs that often cover plains of the north of France and the sea fogs that envelo many of the coast towns, that the Lyonnaise fogs are altogether local. Lyons, situated at the confluence of the two navigable rivers, the Rhône and the Saône, ha a population of over half a million, and, although containing with its suburbs many manufacturing establish
ments, can in nowise be considered smoke infested ments, can in nowise be considered smoke infested. the streets, shutting out sunshine and causing discomfort to the inhabitants.

This fog is really an anomaly, because at a comparatively short distance away from the city there may be absolutely no fog. A strong wind will often clean the town of mist and bring a return of clear weather, whereas in cases of a general fog extending over a vast area a wind may be slow in bringing about a return of normal atmospheric conditions. Furthermore, accord ing to the American Consul at Lyons, the fogs in that city do not spread widely, owing to elevated land about the rivers, and are often low-lying fogs. It has been supposed that local fogs were caused by the converg-
ence at this point of winds from the north or from the ence at this point of winds from the north or from the
Alys with those from the south. A chain of shallow lakes, lying upward of twenty miles away from the town, has been likewise blamed, as well as the dust and smoke inseparable from a large city. Careful observation, however, seems to point to the fact that the constant evaporation of the two rivers in and near the city produces a great deal of humidity, which is the city produces a great deal of humidity, which is
invisible when the temperature is high, but which read- mined. Thus, he found in castrated young males, in which transplantation of ovaries had been practised, that the development of masculine peculiarities is inhibite and female traits substituted, so that the individual tend to assume the female type and become to a striking degree feminized-males, as shown in bodily form, in a development of the mammary glands, in lactation, and in an alteration of psycho-sexual characters. Furthermore, Riddle has found that the ova of the pigeon ar dimorphic, one half having an inherent tendency to produce males and the other half females; that the eggs duce males and the other half females; that the eggs
having the male tendency have a higher per cent of water, a smaller size, and a lower per cent of potential energy and that the "sex-foundation" of the germplasm is transmutable, so that an egg that has inherently the male tendency may become female, and that such females exhibit secondary male sexual characters. The transmutability of the germplasm is comparable in its physicochemical mechanism to the reversion of the maltosedextrose-maltase reaction that is caused by a change in dextrose-maltase reaction that is caused by a change in
concentration of the solution, the dextrose being reverted in to isomaltose and not to the antecedent maltose-the male egg is not changed into a female egg but into a odified or feminized-male egg.

In considering the transmissikility of parental subthe stereoisomerides and intimately positively between are inherent in the parent and those which are acquired are inherent in the parent and those which are acquired
through infection or otherwise. Thus antibodies that are acquired by the mother may be without influence upon the ovary during the formation of the germplasm and not even become a constituent of the latter. On the other hand, an immunity may be established in the mother that may be conveyed to the offspring, yet curiously enough such an immunity may not be transmitted by the immunized male. In processes of the production of the germplasm the ovary may be as insensitive to the presence of many acquired substances of the blood as are ome or all other oryans, and there is no more reason in general for expecting the ovary and its product to be
affected by such bodies or conditions than there is for the pancreas and the pancreatic juice or any other secretory structure and its product to be affected. Every acquired substance must, in its relations to the ovaries, be governed by the same physico-chemical laws as determine specific selectivities or reactivities in connection with the tissues generally. Hence, any such substance may the tissues generally. Hence, any such substance may
be reactive in relation to one structure but not to another. Plasticity as regards sex-determination has been demon-
strated in the studies of the development of a male (drone) bee from the unfertilized egg, and of a female from the fertilized egg. Moreover, the developing female bee when fed $\bullet$ ni ordinary food becomes a common "worker," but when fed on royal foud develops into a queen. and offspring is seen in its simplest manifestations in reproduction among protozoa by binary fission and budding, by which the part separated from the parent mass is in all essential respects like the parent, having the same fundamental physico-chemical composition and constitution. 'That in such instances the offspring should be a vious as that halves of a cube of sugar should be alike. Similarly, if we have in the ovule and sperm forms of protoplasm which as stereochemic systems are in all fundamental respects counterparts of those from which the parents were developed it follows that the offspring must under normal conditions in accordance with the laws of physical chemistry have the same fundamental parental characteristics, as much so as separated portions
of any complex stereochemic system must possess the properties of the initial mass. Moreover, if the stereochemic systems of germplasms of the female and male differ, as must be admitted, it is manifest that the stereochemic system of the egg that has been activated artificially or naturally, as the case may be, must be different, and hence undergo development differences that will be obvious in the offspring. In the first instance, the serial reactions which lead to the formation of the different tissues, etc., are activated by a mere disturbance of physico-chemical equilibrium, which may be due to the conversion of a proenzyme into enzyme or a prosecretift to a secretin, or in other words of an inactive body into an active one. In the second instance, there is not only activation but the extremely important addition of the male stereochemic system which by admixture with the female system constitutes a female-male system. Therefore, in the first place the offspring is developed solely from the female stereochemic system, and in the second place from the combined female and male systems, one or the other of which may be wholly or in part dominant in determining certain peculiarities in the dransmutability of stereoisomerides and the multiphase transmutability of stereoisomerides and the multiphase transmutability of
stereochemic systems, coupled with the reversibility of metabolic processes which may be due to even the simplest of changes in physico-chemical mechanisms, we have a logical basis for the explauation of the phenumena of sexual dimorphism that is expressed in the so-called male and fernale ova, and male and female spermatozea; doxical sex developments where the unfertilized egg develops into either male or female offspring; and of sexual transmutability of the inherently male or female ovule.

It follows upon the basis of our theory that because of the inherent peculiarities of the stereochemic systems of the germplasmls and the definitely predetermined
nature of the entire series of reactions in accordance with the laws of physical chemistry that "like begets like" because like every other physico-chemical phenomenon, individual or serial, under given conditions, it is a physicochemical fatality. ily condenses during cold weather when there is not sufficient wind to drive it away.

Owing to the heights along the rivers, this fog cannot escape except at one side, toward which a part rolls, thins out, and often disappears. In consequence, much confined, the fog thickens and increases in volume over the rivers, quays, and thoroughfares, and becomes injurious to health and interferes with traffic. At certain times the town seems from some points surmounted by an immense dome of mist, the density and height of which vary according to the temperature and the sunshine. In view of the possibility of doing away with the local fogs, the city authorities have determined to essay a systematic campaign against this plague. Certain measures have already been suggested, such as great blowing-machines from the heights above the city, and also the use of Hertzian waves. : The project formulated by M. Onofrio consists in pouring oil on the rivers some distance above the city at a point where the fogs usually collect, so that the surface of the streams will be covered with a thin oil film for a distance sufficient to prevent the rise of vapors within the fog area.

Various facts have been collected from different points, showing the efficacy of the oil coats in reducing the roughness of water, escape of unhealthy odors, and the prevention of rapid evaporation. Experiments have been made by the scientist in question on a small scale with a long vat, at the end of which very hot water was introduced. At the other end there was an openwas introduced. At the other end there was an open-
ing, so that there was a rapid and regular current. From the entire surface thick steam constantly rose At about one quarter of the distance from the inlet a dividing partition was let down in the form of a double sieve, holding tow moistened with a small quantity of oil. Following the current, an oily coating extended over the lower three-quarters of the vat, and immediately vapor ceased to rise. It is estimated that a coating of oil of one 1/100,000 millimeter (the millimeter = ing of oil of one $1 / 100,000$ millimeter (the millimeter $=$
0.039 of an inch) in thickness is sufficient to cause the 0.039 of an inch) in thickness is sufficient to cause
disappearance of the vapor from the boiling water.
This experiment was carried out with water at the temperature of about 185 deg. Fahr., whereas the temperature of the two rivers on which Lyons is situated averages about $59 \mathrm{deg}$. Fahr. ; so it is believed that an exceedingly thin sheet of oil will be still-more efficacious when spread over a cold surface, even should it attain the thinness of $1 / 200,000$ millimeter. The thickness proposed for the rivers is $1 / 150,000$ millimeter, which will require about 0.8 of a gallon for about every 460,000 square meters (552,000 square yards). The oil best suited to this work has not yet been determined. Trials are being made with as many as fourteen different oils-animal, vegetable, and mineral-to find one that will come nearest to fulfilling the required conditions. It should be an oil that will spread rapidly and easily over the surface of the water, and at the same time it must be an oil with the strongest possible power of resistance and tenacity. It is possible, however, that some special preparation will have to be devised to meet the conditions.

An oil film that will readily break on the water is of little value. These two qualities are more or less opposed, and it will require some study to find the oil that will spread most easily and still not break. It is thought that an animal or vegetable oil will be found preferable to a mineral oil, though the mineral oils would probably be a good deal cheaper. It is not possible to give the probable cost of keeping the entire city free of fog before an effective oil has been determined upon, although a rough estimate for both rivers puts the expenditure within $£ 6$ a day for the cold season. It is hoped, through the exhaustive experiments now beginning, to replace the average sixty-two days of fog with which Lyons is annually troubled by sixty-two days of normal weather. If practice bears out a plausible theory, not only will Lyons receive its full share of sunshine, but other inland cities similarly situated and darkened by fog will be enabled to profit by this simple fog-exterminating method.-Journal of the Royal Society of Arts. 